\title{
Impact of the coronavirus disease 2019 pandemic on postgraduate medical education in a Singaporean academic medical institution
}

\author{
Ching-Hui Sia ${ }^{1,2}$, Benjamin Yong-Qiang Tan ${ }^{1,3}$ and Shirley Beng Suat $00^{4,5}$ \\ ${ }^{1}$ Department of Medicine, Yong Loo Lin School of Medicine, National University of Singapore, ${ }^{2}$ Department of \\ Cardiology, National University Heart Centre Singapore, ${ }^{3}$ Division of Neurology, University Medicine Cluster, National \\ University Health System, ${ }^{4}$ Emergency Medicine Department, National University Hospital, National University \\ Health System, and ${ }^{5}$ Department of Surgery, Yong Loo Lin School of Medicine, National University of Singapore, \\ Singapore
}

The coronavirus disease 2019 (COVID-19) pandemic has progressed relentlessly since the first case was reported in Wuhan, China on 31st December 2019. In Singapore, the first case was reported on 23rd January 2020. As the number of cases increased, the government has since escalated the national alert system to the 2nd highest level. Residents have been deployed based on service needs, non-urgent appointments and surgeries have been postponed and inter-hospital rotations have been suspended. As such, postgraduate medical education would have to be reorganized on top of these changes. Specialist training in Singapore follows the Accreditation Council for Graduate Medical Education-International recommendations. In this opinion paper, we share the impact that the COVID-19 pandemic has had on postgraduate education in the National University Hospital, Singapore (Fig. 1).

Increasing service requirements due to the COVID-19 pandemic has challenged the balance between clinical service and medical education. Dedicated pandemic

Fig. 1. Issues Relating to Postgraduate Medical Education that Have Surfaced since the Start of the COVID-19 Pandemic

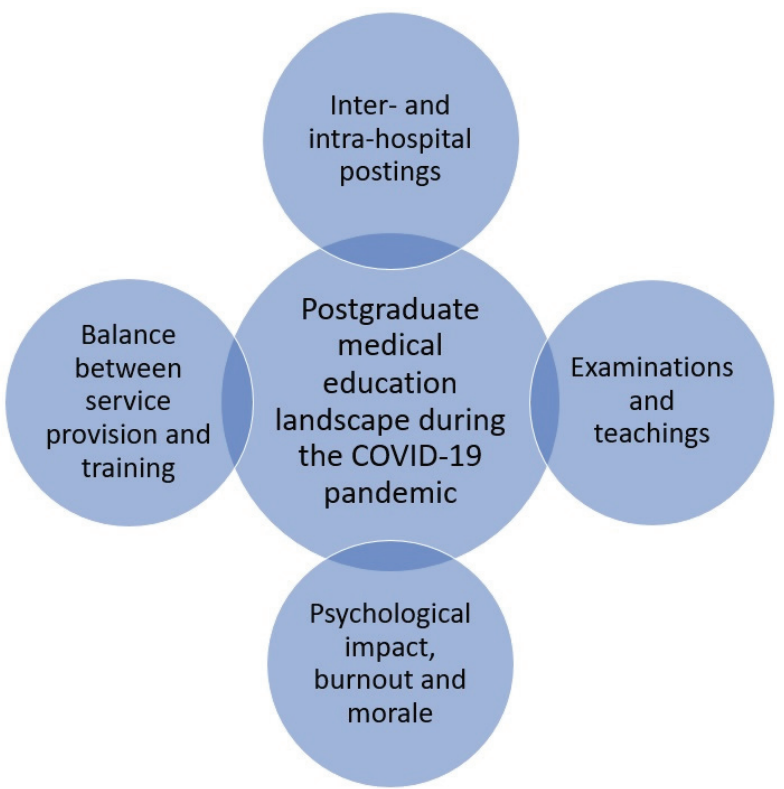

COVID-19: Coronavirus disease 2019.
Received: April 11, $2020 \bullet$ Revised: May 8, $2020 \bullet$ Accepted: May 8, 2020

Corresponding Author: Ching-Hui Sia (https://orcid.org/0000-0002-2764-2869)

Department of Cardiology, National University Heart Centre Singapore, 1E Kent Ridge Road, NUHS Tower Block Level 9, Singapore 119228

Tel: +65.6779.5555 Fax: +65.6779.5678 email: ching_hui_sia@nuhs.edu.sg
Korean J Med Educ 2020 Jun; 32(2): 97-100.

https://doi.org/10.3946/kjme.2020.157

eISSN: 2005-7288

(C) The Korean Society of Medical Education. All rights reserved. This is an open-access article distributed under the terms of the Creative Commons Attribution Non-Commercial License (http:// creativecommons.org/licenses/by-nc/3.0/), which permits unrestricted non-commercial use, distribution, and reproduction in any medium, provided the original work is properly cited. 
teams have been started in the hospital coupled with an augmentation of manpower in emergency department and intensive care units by residents. Residents are being deployed beyond their traditional duties not planned as part of their training rotations. To ease the manpower shortage, some fresh local graduates are being fasttracked into internship 1 week earlier. Turner et al. [1] previously discussed the logical fallacy of a serviceeducation balance given the increasing administrative demands, duty hour limitations and service demands (including service quality and safety) in healthcare in the pre-COVID-19 pandemic period. With an increase in clinical load, there is a challenge for educators to consider alternative methods of providing education on top of service.

National infection control policy has mandated that doctors are not allowed to rotate across hospitals to minimize healthcare transmission, barring exceptional circumstances. Our residency program trains residents at three restructured hospitals and several partner sites including community hospitals and polyclinics. There are also exchanges with other programs from other sponsoring institutions. With the shift in alert level, rotations that could only be fulfilled at certain sites could not continue, and residents at external institutions could not be rotated back. This has disrupted training. Furthermore, to avoid any intra-departmental spread of infection, teachings that used to be held in meeting rooms have been transitioned to an online format. As such, there has been a sharp increase in the use of videoconferencing technology. Whilst using such technology is fairly novel for our institution as the de-facto method of teaching, videoconferencing has been previously shown to be effective even if learners are physically isolated [2]. Educators will need to adopt strategies to maximize the educational potential of videoconferencing [3]. On the upside, teachings in our institution that were previously hospital-based could now be extended to our partner departments from the other hospitals within our cluster, and even to our residents who have rotated to other sponsoring institutions. Recorded versions of these sessions can also be provided to residents for their review later. For surgical residents, due to the reduction in surgical caseload, mitigation measures such as the use of simulators will be needed to upkeep manual dexterity skills.

There has also been an impact on trainees in terms of examinations. Several mandatory summative postgraduate examinations and exit specialist examinations have been postponed or cancelled. This has provoked anxiety in residents as they wonder whether they would be allowed to complete their training. Some medical schools in the United Kingdom have done away with their final examinations, citing student competency assessments during training as being sufficient reflection of ability [4]. This does bring to the forefront the continued debate of the role of a high-stakes summative assessment versus continual assessments. There is a push to reduce the weightage of high-stakes summative assessments to a programmatic one in line with a shift towards competency-based education [5]. This requires a change in perspective by membership colleges and residency faculty. The use of a portfolio might gain renewed interest as well [6]. The alternative is to take adequate precaution. For example, the emergency medicine specialty in Singapore continued with their written examinations, but with strict segregation of candidates from different institutions in different rooms. Exams could also use simulators or standardized patients instead of real patients. The respective specialty residency advisory committees would need to review and recommend modifications to training requirements taking into consideration core competencies for the new training 
environment and constraints present. This pandemic is likely to spark intense discussions into what constitutes good assessment, and how it can best be done [7]

Finally, it is important for medical educators to consider the mental and emotional well-being of residents. COVID-19 can cause significant psychological impact on residents [8]. Prior to the pandemic, resident burnout levels have already been reported to be high [9]. There is a need to implement preventive measures to prevent burnout as the pandemic is projected to last at least until the end of the year. Our institution has made available counsellors that residents can reach out to for advice. Faculty have been looking out for junior staff to ensure that the workload is well balanced and that they receive adequate rest. There are opportunities for the residencies to look into how to build teamwork among residents of different specialties posted to the COVID-19 care areas. Teamwork is crucial in high-risk, highintensity work environments like the frontlines minimize mistakes [10]. Lastly, there needs to be enough personal protective equipment for residents to carry out their duties so that they can focus on clinical care.

The COVID-19 pandemic has brought on new challenges to the postgraduate medical education landscape. Nevertheless, we think it is an invaluable opportunity for educators to innovate to ensure that residents continue to be trained to be brave and competent doctors.

ORCID:

Ching-Hui Sia: https://orcid.org/0000-0002-2764-2869;

Benjamin Yong-Qiang Tan: https://orcid.org/0000-0003-1824-9077;

Shirley Beng Suat Ooi: https://orcid.org/0000-0002-8661-7225

Acknowledgements: None.

Funding: No funding was obtained for this study.

Conflicts of interest: No potential conflict of interest relevant to this article was reported.

Author contributions: CHS and BYQT conceptualized the work, collected data and interpreted the data. All authors were involved in drafting the article and critical revision of the article. SBSO supervised the work overall. All authors gave final approval for this version of the paper to be published.

\section{References}

1. Turner TL, Fielder E, Ward MA. Balancing service and education in residency training: a logical fallacy. JAMA Pediatr. 2016;170(2):101-102.

2. Allsop S, Hollifeld M, Huppler L, et al. Using videoconferencing to deliver anatomy teaching to medical students on clinical placements. Transl Res Anat. 2020; 19:100059.

3. Gill D, Parker C, Richardson J. Twelve tips for teaching using videoconferencing. Med Teach. 2005;27(7): 573-577.

4. Rowan C. Cambridge School of Clinical Medicine cancels all final clinical exams due to COVID-19. https:// thetab.com/uk/cambridge/2020/03/12/cambridge-school-o f-clinical-medicine-cancels-all-final-clinical-exams-due-to-c ovid-19-133911. Accessed April 1, 2020.

5. Rich JV, Fostaty Young S, Donnelly C, et al. Competencybased education calls for programmatic assessment: but what does this look like in practice? J Eval Clin Pract. 2019 Dec 9 [Epub]. https://doi.org/10.1111/jep.13328.

6. Heeneman S, Driessen EW. The use of a portfolio in postgraduate medical education-reflect, assess and account, one for each or all in one? GMS J Med Educ. 2017;34(5):Doc57.

7. Norcini J, Anderson B, Bollela V, et al. Criteria for good assessment: consensus statement and recommendations from the Ottawa 2010 Conference. Med Teach. 2011; 
33(3):206-214.

8. Tan BY, Chew NW, Lee GK, et al. Psychological impact of the COVID-19 pandemic on health care workers in Singapore. Ann Intern Med. 2020:M20-1083.

9. Ferguson C, Low G, Shiau G. Resident physician burnout: insights from a Canadian multispecialty survey.

Postgrad Med J. 2020:postgradmedj-2019-137314.

10. Lerner S, Magrane D, Friedman E. Teaching teamwork in medical education. Mt Sinai J Med. 2009;76(4): 318-329. 